\title{
Research on the Practice of Communication Education Curriculum under the Background of Big Data
}

\author{
Yuan Du* \\ Guangzhou Bo Lian Shang Culture Media Co., Ltd. E-mail: duyuan@163.com
}

\begin{abstract}
With the advent of the information age, the function of big data is becoming more and more powerful in the new era. In the process of news dissemination in colleges and universities, there are many deficiencies that affect teaching efficiency, such as strict teaching methods in traditional teaching mode, insufficient learning initiative of students, and poor practical ability. With the help of information technology and modern big data technology, college news communication technology can create rich and varied teaching environment for students, guide students to practice and promote the improvement of comprehensive quality.
\end{abstract}

Keywords: Universities; Journalism and Communication; Big data; Teaching

\section{Introduction}

With the continuous improvement of China's economic and social development, the implementation of information technology is more and more extensive. With the advent of the era of big data, it is more appropriate to carry out educational activities in colleges and universities. Focusing on the teaching of news communication in colleges and universities, the traditional teaching mode has exposed some shortcomings. Strengthening the application of information technology in the teaching of news communication in colleges and universities will help improve the educational impact. Of course, the teaching of journalism and communication in colleges and universities should also combine the actual situation of students with other targeted teaching forms to cultivate and innovate talents, so as to effectively increase the influence of general education. Strengthening the research on news communication in the field of big data in colleges and universities has important teaching significance and social value.

\section{The analysis of the new situation facing the news communication indus- try from the perspective of big data}

With the advent of the era of big data, great changes have taken place in people's daily life, and daily production has also brought great influence. News communication has always been an important platform for information dissemination, and it faces more challenges in the era of big data. The following two aspects should be actively changed and investigated to effectively improve the overall development efficiency of the industry.

\subsection{Changes in news production methods}

With the advent of the era of big data, the amount of information is expanding, the frequency of information ex- 
change is accelerating, and the types of information data are becoming increasingly diversified, which has brought many influences to the traditional news production mode. At the same time, it is also a new opportunity for the news media industry. The news communication industry can closely combine the changes of the new era and environment, change the traditional management mode, strengthen the unacceptability of ideas, and pay attention to the integration with the Internet platform, so as to better promote the automatic data collection and creation, and improve the sustainability and readability of news communication.

\subsection{Changes in reporting methods}

Under the background of big data era, the public's reading habits and ways have changed. The traditional way of spreading news through newspapers and television is the dominant mode at present, but the emergence of Internet social media makes the news report paradigm more diversified and dynamic, and also makes the news report more time-sensitive. Therefore, the news communication departments need to combine the development requirements of the times and the market demand, and constantly transform and upgrade, in order to better find the way of sustainable development.

\section{The research on the training of news communication talents in colleges and universities from the perspective of big data}

With the advent of the era of big data, the education of news communication ability in colleges and universities is also facing a new situation. The emergence of network carrier makes the teaching of news communication face a new development trend. However, the education of news communication ability in colleges and universities still faces the following problems in the development process.

\subsection{Higher systematic level of curriculum design of journalism and communication specialty}

In the teaching of news communication, it is necessary to carry out the systematic design of professional courses around the market demand and development time, so as to provide better guidance and help for students to practice. At present, many colleges and universities have set up news communication and other related branches, including news, communication, digital broadcasting and radio and television news. Generally speaking, the professional setting of the curriculum is comprehensive, but the specific analysis shows that many problems are still insufficient, such as the combination of social needs in the talent training plan. The curriculum is usually suitable for the media form of a single major, that is, news writing and editing, etc. Some individual modules ignore the overall planning and design of technology, which is often carried out according to the format of a single media part of the major. For new courses such as big data technology, colleges and universities have not combined real-time content supplement with excellence, which leads to a large number of teaching contents being not systematic. Learning is not conducive to cultivating students' interest, and is not conducive to close integration with development and time changes, and timely and effective teaching. In addition, the college pays insufficient attention to the research of applied teaching. The curriculum design is not perfect, the teaching supervision and evaluation work is not fully combined with the goal of cultivating ability, and it is not conducive to improving the educational effect.

\subsection{Teaching without characteristics and level of teachers that needs to be improved}

The teaching of journalism and communication course should pay attention to practicality, improve students' professional skills and accomplishment of journalism, and promote students' practice. However, at present, in the teaching of journalism and communication, teachers are still accustomed to teaching according to the traditional teaching methods, and cannot fully combine the relevant tools in the information age to realize the diversification of teaching modes. Some teachers are accustomed to the traditional way of thinking in teaching design, and they also lack media experience. There are few dual teachers in schools, and they are passive in teaching related knowledge courses. Some teachers' computer professional technology application ability is insufficient, and they can't make full use of information 
technology in teaching. Some teachers are inaccurate in news dissemination and development direction, and teachers' level needs to be improved.

\section{Research on teaching optimization measures of journalism and commu- nication in colleges and universities from the perspective of big data}

\subsection{Clear teaching requirements and evaluation system}

The way and system of achievement evaluation plays an important role in the teaching process of project type. Success rate affects students' enthusiasm for participating in project teaching. Therefore, in project evaluation, the basic knowledge theory can reach $60 \%$ of the total score and $40 \%$ of the application score of project activities. The main reason of this section is that although the course has been translated into practical teaching, it is still very important to master the basic theory. It should be more flexible in the examination questions, not only to master the basic knowledge, but also to investigate the students' expanding thinking in the project implementation activities. The implementation of project activities can be divided into general activity performance and group evaluation. The total score of activity achievement is scored by teachers and students in all classes, and the final project completion is evaluated. The mutual evaluation among group students is that the students of the same group evaluate each other, and the group discussion achievements and cooperation, and comprehensive scores are exchanged for the student group.

\subsection{Establishing a "problem-based teaching plan”}

Project-based teaching is to give students a complete opportunity to study independently and give play to the guiding role of teachers. In this process, we should give full play to teachers' guiding role and realize the organic combination of students' subject and teachers' guidance. First of all, we can carefully check the teaching materials, understand the students' learning needs, create a "problem teaching project" with professional characteristics, and create a "simulated learning scene”. According to the students' learning situation, teachers carefully check the teaching contents and process and refine them properly, formulate project-based teaching plans, and define the objectives, key points and flexible methods, which are suitable for the students' actual working conditions. Secondly, it encourages students' interest in learning. Teachers can stimulate students' learning enthusiasm through competition and extra points, and transform passive learning into active learning. Real-time interaction can keep students' learning enthusiasm and is a way for teachers to guide them. In the process of teacher-student interaction, teachers will ask students about high-quality questions, so that students can discuss, create ideas and debate.

\subsection{Practical training: “Interaction between knowing and doing” and professional quality im- provement}

The high-quality, media-oriented, compound and expert staff training emphasized in the "Excellent Journalism and Communication Talents Training Program 2.0” of the Ministry of Education of China has responded to the internal requirements of "once gender" in the construction of first-class courses, especially the deep integration of knowledge, talents and accomplishments. The characteristics of the orientation of journalism and communication specialty determine the importance and urgency of education, thus pushing the interaction between knowledge and application to an important position in the construction of mixed curriculum, that is, journalism and communication ability should not only master professional theoretical knowledge, but also have the ability to solve professional problems. The key of "interaction between knowledge and action" is to pay attention to the practical content and connection of course teaching. As a matter of fact, teaching practice is not the exclusive content of social practice courses, and it should be placed in the professional courses of journalism and communication, thus becoming a part of teaching content and teaching activity design. Therefore, it has become the basis of improving students' professional quality to strengthen the content of teaching application education of mixed courses and how to ensure the teaching mechanism and technical system.

Planning and organizing teaching practice can be reflected not only as seminars on social issues, but also as spe- 
cial training for specific practical skills. In contrast, the mixed curriculum highlights the practical educational contents such as carefully planned construction, design, organization and implementation. On the other hand, it highlights the chain management of educational process through online real-time teaching connection and MOOC technology system, which means that teachers can dynamically monitor the whole process of training programs and provide immediate feedback and dynamic guidance according to students' implementation progress, thus forming a benign dialogue between theoretical knowledge and practical application of professional ability, and improving the "knowledge interaction” dimension of professional ability. Jinan University's integrated news focuses on the news form in the era of integrated media, and pays attention to students' ability of integrating news theory and practical learning. On this basis, the basic teaching philosophy of integrated journalism is to defend the "teaching and practice in the field of journalism" and strengthen the in-depth analysis and integrated reporting of major issues in the transition period. The application training course in the spring of 2020 is based on the project-oriented teaching concept. In order to improve students' ability to practice fusion thinking, the course paper comprehensively considers the practice of COVID-19 pneumonia epidemic theme-as a group of students, they choose COVID-19 pneumonia. During the epidemic period, public release was presented in five integrated news forms, namely, the " $4+X$ " module of action: " 4 " is a mandatory option, including network reports, short video news, data news and new media audio; For the optional, that is, H5 news, VR news, animation news, news games, new media reports, etc., and the five recent delivery fusion news studies focus on new topics. These studies are published on WeChat public number for students and teachers to communicate in School of Journalism and Communication, Jinan University.

\subsection{Strengthening the innovation of educational concept and improve the curriculum system of journalism and communication specialty}

On the one hand, we should fully understand the influence of big data era on news communication industry, pay attention to the innovation of news communication concept, persist in continuous improvement and innovation in teaching objectives and personnel training mode, better explore the innovative discovery of teaching concept around the goal of cultivating basic literacy, and bring more subject contents into the target system of professional personnel training.

On the other hand, we should continue to develop and innovate the curriculum system of journalism and communication specialty, make full use of the boundary content of the new data age, develop higher-quality curriculum resources and build an information sharing platform with related courses such as data mining and data visualization, learn from foreign teaching models in the field of journalism and communication, and combine with the actual curriculum characteristics of schools, so that we must constantly improve the modernization level of personnel.

\section{References}

1. Bu L. Reconstruction and approach of journalism and communication research in the era of big data (in Chinese). TV Guide China 2018; (5): 55, 57.

2. Liu Y. Thoughts on the reform of journalism and communication education in universities in the era of big data (in Chinese). Wencun Yuekan 2018; (11): 56. 